\title{
Köprü Kuran Sosyal Sermaye, Psikolojik Sahiplenme ve Birey-Örgüt Uyumu Arasındaki İlişkilerin İncelenmesi
}

DOI: $10.26466 /$ opus. 867368

Gökhan Uludağ* - Berat Çiçek** - Mehmet Ali Türkmenoğlu ***

${ }^{*}$ Dr, Emniyet Genel Müdürlüğü, Ankara/Türkiye

E-Posta: guludagg@hotmail.com

ORCID: $0000-0003-4763-7511$

** Doç. Dr., Malatya Turgut Özal Üniversitesi, Sivil Havacılık Yüksekokulu, Malatya/Türkiye

E-Posta: berat.cicek@ozal.edu.tr

ORCID: 0000-0002-4584-5862

*** Dr. Öğr. Üyesi, Muş Alparslan Üniversitesi, İktisadi ve İdari Bilimler Fakültesi, Muş/Türkiye

E-Posta: $\underline{\text { m.turkmenoglu@alparslan.edu.tr } \quad \text { ORCID: } 0000-0001-5668-2184}$

Öz

Yirmi yıl önce ortaya atılan psikolojik sahiplenme kavraminn sonuçlar ile ilgili çokça araştırma yürütülmesine rağmen bu kavramı etkileyen etmenler üzerinde görece az durulmuştur. Yazından yola çıkarak, bu çalı̧̧mada köprü kuran sosyal sermaye gibi sosyal birliktelĭgi oluşturan bir olgunun psikolojik sermayenin bir öncülü olup olmayacă̆ı merak edilmiştir. Dolayısıyla, bu çalışmanın amacı köprü kuran sosyal sermayenin psikolojik sahiplenmeye etkisinin incelenmesi ve bu ikili arasindaki ilişkide birey-örgüt uyumunun aracilık rolünü ortaya koymaktır. Bu amacı gerçekleştirmek için nicel araştırma yöntemlerinden yararlanılmıştır. Polis Meslek Eğitim Merkezlerinde eğitim gören 259 öğrenciden anket tekniğiile toplanan veriler Yapısal Eşitlik Modellemesi (YEM) yaklaşımı ile analiz edilmiştir. Yapılan analiz sonuçlarnna göre sosyal sermayenin psikolojik sahiplenmeye pozitif bir etkisi olduğu ortaya çıkmış olup, birey-örgüt uyumunun bu ilişkiye aracillk ettiği sonucuna ulaşılmıştır. Değişkenlerin ele alınıs şekliyle çallşmanın özgün olduğu söylenebilir. İlgili yazına katkı sunmanın yani sırra, araştırmanın sonuçları ı̧̧ı̆̆ında çalı̧̧an ve yöneticilere yönelik birtakım öneriler sunulması da hedeflenmiştir. Çallşmanin sinurllikları ve gelecek araştırmalara yön verecek öneriler paylaşılmıştır.

Anahtar Kelimeler: Psikolojik Sahiplenme, Köprü Kuran Sosyal Sermaye, Birey-Örgüt Uyumu, Yapısal Eşitlik Modellemesi. 


\title{
Interrogating the Relationships between Bridging Social Capital, Psychological Ownership and Person-Organization Fit
}

\begin{abstract}
Although there has been plenty of studies examining the results of the concept of psychological ownership, which was introduced twenty years ago, yet relatively less attention has been paid to the factors affecting this concept. Based on the literature, we wondered if bridging social capital, a phenomenon forms social coexistence, would be a determinant of psychological capital. Hence, the aim of this study is to examine the effect of bridging social capital on psychological ownership and reveal the mediating role of person-organization fit in the relationship between these two variables. For this purpose, quantitative research methods were used to achieve this aim. The data collected from 259 students studying at Police Vocational Training Centers were analyzed by Structural Equation Modeling (SEM) approach. According to the results of the analysis, social capital had a positive effect on psychological ownership and person-organization fit mediated this relationship. It is argued that the study is original with the way of incorporating the variables. In addition to contributing to the relevant literature, it is also aimed to provide some suggestions for employees and managers in the light of the results of the research. Also, the limitations of the study and the future directions were shared.
\end{abstract}

Keywords: Psychological Ownership, Bridging Social Capital, Person-Organization Fit, Structural Equation Modeling. 


\section{Giriş}

1970'li yıllardan günümüze kadar olan örgütsel davranış yazını incelendiğinde örgütsel bağlılık, vatandaşlık, adanmışlık gibi çalışanların ve örgütlerin performansını artıran olgular üzerine yürütülen çalışmalarda ciddi bir artıs gözlemlenmektedir. Bu artan ilgi araştırmacıları yeni kavramların keşfine yönlendirmiştir. Nispeten yeni kavramlardan biri de 2001 yılında kullanılmaya başlanan psikolojik sahiplenme kavramıdır. Pierce ve arkadaşlarının 1991 yılında kavramsallaştırdıkları sahiplik olgusuna bina edilen psikolojik sahiplenme, bireyin kuruma karşı resmi bir sahiplik durumu olmasa dahi bireyin kurumu sahiplenmesi ve kurumun kendisininmiş gibi hissetmesi fikrine dayanur (Pierce, Rubenfeld ve Morgan, 1991; Pierce, Kostova ve Dirks, 2001). Psikolojik sahiplenme gerçekleştiğinde birey, kuruma yönelik bağlılık ve sorumluluk duyguları geliştirir. Bunun sonucunda bireyin kuruma olan aidiyet hissi artacağı araştırmacılar tarafından ortaya konulmaktadır (Derin, 2018). Öte yandan, psikolojik sahiplenmeyi ele alan yerel ve yabancı yazındaki çalışmaların bulgularına bakıldığında psikolojik sahiplenmenin sonuçları ile ilgili görece fazla araştırmalar yürütüldüğü görülmektedir çünkü psikolojik sahiplenme birey davranışlarında gözle görülür bir değişim sağlayabilmektedir (Mayhew, Ashkanasy, Bramble ve Gardner, 2007; Akçin, 2018). Ancak psikolojik sahiplenmenin hangi etmenler tarafindan ne kadar etkilendiğini oraya koyan öncüllerini inceleyen araştırma sayısı sınırlıdır (Ötken, 2015). Yazındaki bu boşluk psikolojik sahiplenmeyi belirleyen faktörlerin neler olabileceği ve hangi durumlarda psikolojik sahiplenmenin ortaya çıkabileceği sorularını akla getirmektedir. Bu bağlamda psikolojik sahiplenmenin görece yeni bir olgu olması ve diğer değişkenler ile ilişkisinin daha iyi anlaşılması gerektiği göz önünde bulundurulduğunda bu alanda daha fazla çalışmaya ihtiyaç olduğu söylenebilir. Bu çalışmada ise köprü kuran sosyal sermaye değişkeninin psikolojik sahiplenmeye olan etkisi merak edilmektedir.

Bir varlık biçimi olarak tanımlanan sermaye, ekonomi bilimine ait bir kavram olmasına rağmen kapsayıcılığı nedeniyle psikoloji, sosyoloji ve iktisat alanlarında yaygın bir biçimde kullanılmaktadır. Kapital olarak da adlandırılan sermaye elde edilecek getiriler için kullanılan kaynağı ifade etmektedir. Ekonomi disiplininde işgücü ve teknoloji ile birlikte üretimin ve kalkınmanın devamlılığını sağlayan sermaye önemli bir kaynak olarak 
görülmektedir. Ancak düşünürler sermayenin sadece ekonomik formda değerlendirilmesinin eksik olacağı aslında, sermayenin sosyal ve kültürel formlarda var olduğunu vurgulamaktadır (Bourdieu, 1986). Kültürel sermaye bireylerin eğitim, bilgi ve beceri gibi sosyal varlıkları içerirken, sosyal sermaye insanlarla olan etkileşim sonucu ortaya çıan bir ürün olarak görülmektedir (Steinfield, Ellison ve Lampe, 2008). Son zamanlarda bu kavram örgüt araştırmacılarının da dikkatini çekmektedir ve özellikle sosyal sermayenin iş hayatında çalışanların iş tatminini ve iş performansını arttıran bir motivasyon kaynağı olduğu vurgulanmaktadır (Gerşil ve Aracı, 2011; Şahin ve Y1lmaz, 2020). Bu bakımdan sosyal sermayesi yüksek olan bireyler örgütlerin başarısında anahtar role sahip olduğu söylenebilir.

Bireylerin kuruma bağlılığını etkileyen ve bireylerin işbirliğini sağlayan bir başka kavram ise birey-örgüt uyumudur. Adından da anlaşılacağı üzere birey-örgüt uyumu bireylerin örgütleri ile olan uyumluluk durumunu ifade eden bir olgudur (Turunç ve Çelik, 2012). Bazı araştırmacılar birey-örgüt uyumunu bireyin kişilik özellikleri ile örgütün iklimi arasındaki ahenk olarak tanımlarken (Kristof, 1996), bazıları ise bireylerin değer yargıları ile örgütün değerlerinin örtüşme derecesi olarak ifade etmişlerdir (Verquer, Beehr ve Wagner, 2003). Alanyazındaki çalışmalar incelendiğinde bireyörgüt uyumunun örgütsel vatandaşlığ ve örgütsel bağlllığ1 arttırdığ1 ortaya konmuştur (Silverthorne, 2004). Buradan hareketle çalışan davranışlarını etkileyen rolü nedeniyle birey-örgüt uyumu bu çalışmada şartlı değişken olarak ele alınmış olup köprü kuran sosyal sermaye ile psikolojik sahiplenme arasındaki ilişkide nasıl bir rol oynayacağı merak edilmektedir. Yukarıdaki ifadelerden yola çıkarak, bu makalenin amacı sosyal sermayenin psikolojik sahiplenmeye olan etkisini incelemek ve bu iki değişken arasındaki ilişkide birey-örgüt uyumunun aracı rolünü anlamaya çalışmaktır.

\section{Teorik Çerçeve}

\section{Köprü Kuran Sosyal Sermaye}

Sermaye kelimesi günlük alanda kullandığımız ve en basit tabirle birikim olarak ifade ettiğimiz ekonomik alanda önem verilen kavramlardan birisidir. Sosyal sermaye ise birçok bilim dalının konusunu oluşturmaktadır. Köprü kuran sosyal sermaye ise bunun alt bileşenlerinden birisidir. Köprü 
kuran sosyal sermayenin anlaşılması için öncelikli olarak sosyal sermaye kavramını anlaşılmasında yarar vardır. Kavramla ilgili ilk tanımlamalarda bulunan Lyda J. Hanifan, sosyal sermayenin insanların günlük yaşamı içerisinde önem arz eden somut maddelerin aksine; sosyal birlikteliği oluşturan; iyi niyet hali, arkadaşlık ilişkisi, sempati duygusu gibi bireyler ve aileler arasındaki sosyal ilişkiler olarak ifade etmiştir (Hanifan, 1916). Temple bu tanımı en az iki kişi arasında güven odaklı olarak gerçekleştirilebilen iletişim imkânı, başka bir açıdan, toplumu oluşturan bireyler, stk'lar ve kamu kuruluşları arasındaki koordinasyon ilişkilerini daha kolay bir hale getirerek toplumun üretkenliğini yükselten, güven, norm ve iletişim ağı özellikleri şeklinde ifade etmiştir (Temple, 2000). Sosyal sermaye alanında önemli katkısı olan kişilerden birisi de James Coleman'dır. Coleman Sosyal Sermayeyi; İnsanların hedeflerini gerçekleştirebilmek için grup olarak ya da örgüt şeklinde ortak çalışabilme yeteneği şeklinde tanımlamıştır (Coleman, 1988). Tanımlardan anlaşıldığı üzere sosyal sermaye birden çok insanın belirli hedefler doğrultusunda bir araya gelerek güven endeksli bir ağ oluşturması olarak karşımıza çıkmaktadır

Sosyal sermayenin çeşitli bileşenleri bulunmaktadır. Bu bileşenlerden ilki gerek insanların birbirine karşı gösterdiği gerekse farklı toplumsal gruplar arasındaki güven düzeyidir. Bir diğersi ise; yazılı ya da yazısız davranış ve kurallardan oluşan normlardır. Bir başka bileşen ise iletişim olanakları, sosyal ağlardır (Karagül ve Dündar, 2006). Normlar güven duygusunun aracı unsuru olarak görülür ve aynı zamanda aktörlerin zaman içerisinde nasıl bir davranış sergileyeceğini gösterir (Reyhanoğlu, 2006). Sosyal ağların ise ilişkilerin yanı sıra, iletişimi tasarladığı ifade edilmektedir (Öğüt ve Erbil, 2009).

Sosyal sermaye farklı boyutlardan oluşmaktadır, bunlardan birisi de köprü kuran sermayedir. Bu tip sosyal sermaye ile ilgili tanımlara bakıldığında ise; enformasyon yayan ve farklı insanlar arasında gerçekleşebilecek tanışları birbirine bağlayan genelleştirilmiş güven ağları şeklinde ifade edilmiştir (Pennington, 2014). Farklı bölgelerde yaşayan insanların ve toplulukların ilişkilerini ele almaktadır. Köprü kuran sosyal sermaye türünde kurulan ilişki, farklı coğrafyada hayatını devam ettiren, farklı sosyoekonomik özelliklere sahip insanlar arasında gerçekleşmektedir (Tüysüz, 2011). Harpham; diğer grup ya da topluluklarla gerçekleştirilen ve insanların gelişiminde önemli bir etki gösteren resmi ve gayri resmi bağlantıları 
kapsadığını ve köprü kurmanın, güç oranı itibariyle farklı orandaki insanlar arasındaki bağlantılara işaret ettiğini söylemiştir (Harpham, 2008). Köprü kuran sosyal sermaye sayesinde farklı çevrelerden gelen kişiler, tek başlarına mümkün kılamayacaklarını zannettikleri konuları uygulamaya geçirerek öncesinde herhangi bir ilişki kurmadıkları ağlara girmekte ve bu ağlarda ortak faaliyetlerde bulunmaktadırlar (Eşki, 2009). Köprü kuran sosyal sermaye ile faklı sosyal çevrelerden gelen insanların farklı kültürleri, farklı iş alanları farklı tecrübeleri ve farklı sosyal bağlantıları göz önünde bulundurulursa büyük bir zenginlikten bahsedilebilir. Ancak bu zenginlikleri ortak payda da buluşturabilmenin yolu bu kişiler arasında güven duygusunun yeterli seviyeye çıartılması ile gerçekleşebilir. Güven duygusunun oluşmasıyla ortak iş yapma, karşlıklı fikir zenginliğini aktarma daha kolay gerçekleşecektir.

\section{Birey-Örgüt Uyumu}

Günümüzde bireyler hayatlarını idame ettirebilmek için çeşitli örgütlerde çalışmakta ve yaptıkları iş ve pozisyonlarına mukabil maaş almaktadırlar. Bireylerin çalıştıkları örgütleri ile olan ilişkileri onların başarı oranlarına, mutluluk oranlarına, işe devam etme ya da ayrılma duyguları vb. etmenler üzerinde oldukça önemlidir. Bu nedenle bireylerin örgütleri ile olan uyumları yönetim alanının önemli konuları arasına girmektedir.

Öncelikli olarak uyum kavramı üzerinde durulursa; Uyum insanların iç ve dış çevre ile ilişkilerini bozmayacak şekilde iletişim halinde olması durumudur (Başaran, 2004). Bu tanımdan yola çıkarak birey- örgüt uyumunun insanların görev yaptıkları örgütle olan iletişim hali olarak belirtebiliriz. Ayrıca birey-örgüt uyumuna ilişkin tanımlara bakılırsa;

Birey-örgüt uyumu, bireyin sahip olduğu özellikler ile örgütün özellikleri arasındaki uyum seviyesi şeklinde belirtilmektedir (Muchinsky ve Monahan, 1987). Birey-örgüt uyumu, bireysel değer yargıları ile örgütün değer yargıları arasındaki uyumluluk olarak da ifade edilmiştir (Goodman ve Svyantek, 1999).

Birey-örgüt uyumu yönetimi ilgilendiren bir konu olmakla birlikte psikoloji alanından geçiş yaptı̆̆ bilinmektedir. Yönetim bilimi içerisinde 1950'li yıllarda ismini duyurmaya başlamıştır. Sonraki dönemde ise; meslek 
gruplarında, doğru iş tercihinde, örgütsel çevre anlayışında bireyler uyum teorilerine önem vermeye başlamışlardır (Xiaojun ve Shizong, 2010).

Birey-örgüt uyumunun ilişkili olduğu kavramlar bulunmaktadır. Özellikle değerler ve ihtiyaçlar, bu kavramlar arasında ön plana çıkmaktadır. Değerler bir davranış tarzının bir başka davranış tarzına tercih edilmesine yol açan inançlardır. İhtiyaçlar ise geniş bir alanı kapsamaktadır. Maslow ihtiyaçları beş kategoride toplamıştır İlk kategoride fizyolojik ihtiyaçlar, ikinci olarak güvenlik ihtiyacı, üçüncü olarak ait olma ihtiyacl, dördüncü olarak kendine güven ve pramitin tepesinde ise kendini gerçekleştirme arzusunun olduğu bilinmektedir. (Robbins ve Judge, 2017). Uyum sağlanırken bu ihtiyaçlar göz önünde bulundurulmalıdır.

Örgütlerin başarılı olabilmelerinin alt yapısında birey-örgüt uyumu stratejik bir yere sahiptir. Örgütler görevlendireceği personeli seçerken ve görev alanını belirlerken birey-örgüt uyumunu göz önünde bulundurmalıdırlar. Rekabet ortamının giderek artmasıyla, birey-örgüt uyumu ihtiyacı geçmiş yıllara nazaran daha önemli bir yer tutmaktadır (Saldamlı, 2009). Birey-örgüt uyumunun olumlu ve olumsuz sonuçlar doğurması mümkündür. Birey-örgüt uyumu sonuçlarına bakılırsa en önemli sonucun birey ve örgüt arasında kurulan güven unsuru olduğu söylenebilir. Güven unsuru bireyleri örgüte çekmesi ve karşılıklı fayda sağlaması nedeniyle hem bir sebep hem de bir sonuç olabilmektedir. Güven unsuru sayesinde birey ve örgüt zamanla karşılıklı davranışları ön sezinleyebilir, bu sayede iş hayatı daha kolay bir hal alır (Doney ve Cannon, 1997). Örgütlerin kendilerine katkı sağlayan personellerini kaybetmemesi ve onlardan en üst düzeyde yararlanmaları gerekmektedir. Bu personellerin farklı örgütlerde çalışma arayışına girmemesi için, personelin uyumlu çalışabileceği bir atmosfer oluşturmak gerekmektedir. Nitekim bu uyum sağlanırsa personelin kendi kabiliyetlerini daha fazla göstermesinin daha mümkün olacağ düşünülmektedir. Örgütler, personel tercihinde, bireylerin sahip oldukları kabiliyet ve kişilik özelliklerinin sadece işe göre değil aynı zamanda örgüt yapısına da uygun olacak bir sistem kullanmaktadırlar (Bowen vd., 1991). $\mathrm{Bu}$ durum örgütlerin kendi kültürlerini oluşturmaları açısındanda önemlidir.

Birey-örgüt uyumuna yönelik değişik yaklaşımlar ve tasniflerin olduğu bilinmektedir. Ulutaş; birey-örgüt uyumuna yönelik üç yaklaşımdan bahsetmiştir (Ulutaş, 2011): Bunlardan ilki, değerlerde uygunluktur; insanların 
karşılaştıkları farkı durumlarda önemli hususlara odaklanılan uzun süreli inançlardır. Örgütün ve bireylerin değerlerinin uyumlu olması değerlerde uygunluk şeklinde ifade edilmektedir. İkincisi ise, bireylerde uygunluk durumudur. Bireyin kendi kişilik özellikleri ile aynı ortamda görev alan kişilerin karakter özelliklerinin uygunluk durumudur. Sonuncusu ise; işçevre uygunluğudur; bu ise kişinin çevresi ile olan uygunluğudur. Bu üç uyumun yakalanması ile hem örgütlerin hem de bireylerin hedeflerine daha kolay ulaşabileceği öngörülmektedir.

\section{Psikolojik Sahiplenme}

Örgütler içinde önem arz eden kavramlardan bir diğeri de psikolojik sahiplenme kavramıdır. Psikolojik sahiplenmeyi anlamak için öncelikle sahiplenmenin net olarak anlaşılmasında yarar vardır. Günlük hayat içerisinde çok fazla kullandığımız kelimelerden birisi de sahiplik kavramıdır. Benim evim, benim arabam, benim kıyafetim derken kişinin kendisinin kullanım hakkının olduğu ve zilyetlik durumu ifade edilmektedir. Sahiplik kavramından daha çok maddi unsurlar ön plandadır. Sahiplik kavramı insan davranışlarında çok geniş bir yere sahiptir. Kardeşlerin birbirleriyle olan sorunlardan uluslararası diplomatik problemlere kadar bu kapsamda yer almaktadır. Ekonomik, dini, yasal ve sosyal statü kararları sahipliğin belirlenmesine dayanmaktadır (Gelman, Manczak ve Noles, 2012). Psikolojik sahiplenme de ise kişinin maddi olarak sahip olduğu bir varlık yoktur.

O'Reilly, çalışmasında psikolojik sahiplenmenin personelin işletmenin uzun dönemli çkarlarını korumaya yönelik karar verme sorumluluğuna sahip olduklarını düşündüren bir duygu şeklinde belirtmiştir (O'Reilly, 2002). Brown vd. psikolojik sahiplenmenin örgüt içerisinde personelin nesnelere karşı gösterdikleri sahiplik bağlılık duygusuyla, sahip olduklarına karşı değer vermesini, sorumluluk taşımasını ve olumsuz durumlara karşı endişe duymasına neden olacağın belirtmiştir (Brown vd., 2014). Pierce ve Jussila (2011) psikolojik sahiplenmeyi, personelin yaptıkları görevleriyle ve örgüt arasında kurdukları psikolojik ilişkiyi yansıtan çok sayıda unsurdan birisi olarak belirtmişlerdir. Bu unsurlardan her biri personeli hem işe hem de örgütlerine bağlayan bir bağlantı aracı şeklinde değerlendirilmektedir (Pierce ve Jussila, 2011). Vandewalle vd. (1995) psikolojik sahiplenmeyi, personeli kanuni ve maddi açıdan bir sahiplikleri olmamasına karşılık, iş ve 
örgütlerine karşı sergiledikleri sahiplenme duyguları hissetmeleri olarak tanımlamışlardır (Uçar, 2017). Tanımlara bakıldığında her ne kadar personelin resmi olarak sahip olduğu bir unsur olmasa da gönül bağı kurduğu bir unsurun varlığı dikkat çekmektedir.

Psikolojik sahiplenme ile ilgili yapılan araştırmalara bakıldığında psikoloji ve sosyoloji araştırmaları içerisinde geçmiş dönemlere kadar gittiği bilinmektedir. Örgütleri ilgilendiren ve özellikle psikoloji alanında Pierce ve arkadaşları tarafından gerçekleştirilen çalışmalarla öne çıtığı görülmektedir (Uçar, 2016). Her iki bilim dalı da insanlar arası ilişkilerde ve insanların kendi dünyasında aldıkları kararlarda önemli bir yere sahiptir.

Psikolojik sahiplenmenin farklı alanlarla kendini göstermesi mümkündür. Bunlar; projeler, iş tutumları ve nesnelerin farklılığı doğrultusunda ortaya çıkabilir (Wagner vd., 2003). İşletmelerin başarılarına etki eden çok sayıda etken bulunmaktadır. Bazı etkenler başarıyı aşağıya çekerken bazı etkenlerde yukarı yönlü bir etki gösterebilmektedir. Personelin görev aldıkları örgüte sevgi beslemeleri ve kendilerini o örgütle uyumlu ve bir unsuru olarak görmeleri son derece önemlidir. Örgütlerin personeline bu konularda gerekli desteği sağlamaları personelin daha fazla çaba harcamalarına ve örgütün rekabet üstünlüğünü elinde bulundurmasında önemli bir fonksiyon olarak kendisini göstermektedir. Bu doğrultuda personelin maddi unsurlarla olmasa bile psikolojik olarak kendilerini örgütlerinin sahibi olarak görmeleri önemli bir yer tutmaktadır (Yıldız, 2016). İnsanların kendilerine ait işyerlerinin kazancı ve zararı pozitif ya da negatif olarak duygularını etkileyebilmektedir. Bir kamu kurumunda çalışan personelin ya da gelişen şartların kendisini etkilemeyeceğini düşünerek başkasına ait özel bir işletmede çalışan personelin pozitif ve negatif duyguları yakalayabilmesinde psikolojik sahiplenme oldukça önemlidir.

Psikolojik sahiplenme duygusu ile birlikte özellikle ekip halinde çalışan kişilerin kendilerini ben yerine biz olarak tanımlamaları, ortak bir düşünce anlayışına sahip olmalarına yol açacaktır. Ayrıca bu anlayış örgütün hedefine ulaşması ve verimliliğinin artırılması noktasında elzemdir (Mahsud ve Hao, 2017). Isşletmelerin yakaladıkları başarı sadece işletme için değil, personel içinde birçok maddi ve manevi kazanım açısından değerli olduğu bilinmelidir. 


\section{Değişkenler arası ilişkiler ve hipotezlerin geliştirilmesi}

Köprü kuran sosyal sermaye insanlara çeşitli imkânlar sağlamaktadır. Genel olarak bakıldığında; köprü kuran sosyal sermaye ya da bölge dışı bağlar uzak ilişkiler üzerine yoğunlaşmaktadır. Dış bağlar insanlara yeni fırsatlar sunan ve yeni projelere vesile olan faaliyetler olarak değerlendirilmektedir. Köprü kuran sosyal sermayenin aktif hale dönüştürülmesi pozitif katkı sağlayan kaynaklara ve bilgiye ulaşma noktasında yardımcı olmaktadır (Callois, 2005). Bu tip sosyal sermaye sayesinde insanlar yeni kişilerle tanışmaktadır, bu tanışmalar insanların farklı özelliklere ve faklı yeteneklere sahip insanların olumlu yönlerinden istifade edebilmeleri noktasında iyi bir fırsattır. İnsanları yeni becerileri elde etmesi, yaptıkları işi özümsemeleri ve kabiliyetlerini göstermeleri noktasında psikolojik sahiplenme anlayışı ile paralellik gösterebilmektedir. Köprü kuran sosyal sermayenin gerçekleştiği birçok alan bulunmaktadır. Bunlar arasında başı çekenler içerisinde hiç şüphesiz üniversiteler, meslek yüksekokulları ve kolejler gelmektedir. Üniversitelerdeki öğrencilerin geleceğe yönelik hazırlanması için yeni araştırmaların yapılması oldukça önemlidir (Çınar ve Temelli, 2017). Üniversiteler birçok farklı bilim dalında ileri seviyede vermiş olduğu eğitimlerle öğrencileri araştırma ve öğrenmeye yönlendirmektedir. Bu durum öğrencilerin yeteneklerini artırarak üniversiteden elde ettikleri kazanımlarla

yetkinlik elde edebilmektedir (Etcheverry, 1996). Öğrencilerin etkileşiminin yüksek olduğu eğitim kurumları, sosyal sermayenin yoğun bir şekilde gerçekleştiği ve kariyer geliştirme firsatı tanıyan önemli kurumlar arasında yer almaktadır (Işık vd., 2019; Işık ve Çiçek, 2020). Gerek insanlara yeni imkânlar sağlaması gerekse de kişisel gelişimde önemli bir yeri olan köprü kuran sosyal sermayenin, insanların işlerine sahiplik hissetmesine katkı sağlayacağı düşünülmektedir. Bu doğrultuda çalışmanın birinci hipotezini şöyle kurmak uygun olacaktır:

H1: Köprü kuran sosyal sermayenin psikolojik sahiplenme üzerinde pozitif yönlï etkisi vardır.

Köprü kuran sosyal sermaye farklı kültürlerden gelen insanları bir araya getirerek bilmedikleri konularda fikir sahibi olabilmelerinde önemli bir etkendir. Özellikle bir araya gelerek ortak iş kurmak isteyen insanlar açısın- 
dan iyi bir fırsat unsurudur. Birlikte iş kuran ve ticaret yapan insanların birbirine muhalif hareket etmemesi gerekmektedir. Köprü kuran sosyal sermaye, pas sökücü özelliği sayesinde olup toplumun farklı kesimleri arasındaki ağları daha etkin hale dönüştüren bir özelliğe sahiptir (Putnam vd., 2001). Bu noktada uyum faktörü devreye girmektedir. Birey-örgüt uyumunda olduğu gibi uyumun birçok açıdan olumlu etkilerinin olacağ1 düşünülmektedir. Çünkü uyumluluk, bireyleri daha aktif çalışmaya yönlendirmektedir (Xiaojun ve Peilan, 2009). Önceki araştırmalar ve yukarıdaki açıklamalar dikkate alındığında çalımanın ikinci hipotezini aşağıdaki gibi kurmak uygun olacaktır:

\section{H2: Köprü kuran sosyal sermayenin birey-örgüt uyumu üzerinde pozitif yönlï etkisi vardır.}

Psikolojik sahiplenme örgüt içinde birçok tutumun öngörücüsü olarak kendisini göstermiştir (Jussila vd., 2015). Psikolojik sahiplenmenin örgüt yararına birçok olumlu çıtısından söz edilebilir (Van Dyne, 2004). Bu doğrultuda psikolojik sahiplenmeyi yükseltebilecek anlayışların devreye sokulmasında yarar görülmektedir.

Kişilerin örgütlerini sahiplenmesi noktasında önemli tutum ve davranışları artırmak gerekmektedir. Hem birey hem de örgütler açısından pozitif katkı sağlayan ve birçok olumsuz sonucun önüne geçen kavramlardan birisi de birey-örgüt uyumu anlayışıdır. Yapılan çok sayıda çalışma bu durumu kanıtlamıştır (Örneğin: Erkutlu, 2015). Örgütlerde görev alan personelin işine giderken heyecanla gitmeleri ve yaptıkları işten haz almaları için örgüt ortamında gerekli uyumun yakalanması gerekmektedir. Birbirlerinin işine yardıma koşan çalışanlar ve uzmanlık alanı üzerine görevlendirilen personelin sahiplik duygusu taşıması öngörülmektedir. Bu bağlamda çalışmanın üçüncü hipotezi şu şekilde kurulması uygun olacaktır:

\section{H3: Birey-örgüt uyumu psikolojik sahiplenmeyi pozitif etkiler.}

Köprü kuran sosyal sermaye ile birey-örgüt uyumunun ortak noktaları bulunmaktadır. Örnek vermek gerekirse, güven unsuru her iki anlayış açısından da önemli bir etkendir. Hem köprü kuran sosyal sermaye hem de birey-örgüt uyumunda önem arz eden konu güven duygusudur. Köprü 
kuran sosyal sermayenin insanlar üzerindeki olumlu etkilerinin gerçekleşmesi için farklı kültürlerden gelen insanların arasında güven duygusunun yüksek düzeyde gerçekleşmesi gerekir. Nitekim birbirine güvenmeyen insanlar yakınlık kurmaktan kaçınacaklardır. Güven duygusu aynı köprü kuran sosyal sermayede olduğu gibi birey-örgüt uyumunda oldukça önemlidir. Karşılıklı olarak güven duygusunu geliştirmek, belirsizliklerin ortadan kaldırılmasında yardımcı olmaktadır (Jih vd., 2007).Yukarıdaki açıklamalar ışı̆̆ında çalışmanın dördüncü hipotezi aşağıdaki gibi oluşturulması uygun olacaktır:

H4: Birey-örgüt uyumu, köprü kuran sosyal sermaye ile psikolojik sahiplenme arasındaki ilişkiye aracılı eder.

\section{Yöntem}

Bu çalışmanın temel amacl, köprü kuran sosyal sermayenin psikolojik sahiplenme üzerindeki etkisini ve bu iki değişken arasındaki ilişkide bireyörgüt uyumunun aracllık rolünü tespit etmektedir. Bu amaç doğrultusunda oluşturulan hipotezleri test etmek için nicel araştırma yönteminden yararlanılmıştır. Veriler, polis okullarında eğitim gören öğrencilerden anket tekniğiyle toplanmıştır. Bu araştırmanın etik kurul izni Muş Alparslan Üniversitesi Bilimsel Araştırma ve Yayın Etiği Kurulunun 29/12/2020 tarihli ve 10879717-050.01.04-15718 sayılı kararına göre alınmıştır. Anketler, katılım oranını artırmak ve katılımcıların kendilerini rahat hissedecekleri şekilde cevaplamalarını sağlamak için bırak-topla yöntemiyle uygulanmıştır (Lovelock vd., 1976). Elde edilen verilerin analizinde yapısal eşitlik modellemesi yaklaşımı benimsenmiştir. YEM, sosyal bilimlerde ve davranış bilimlerinde araştırmacılar tarafından kurulan modelleri açıklamak için sıklıkla kullanılan bir yaklaşımdır (Weston ve Gore, 2006). Bunun temel nedeni YEM'in, teorik ve ampirik çalışmaların istatistiki olarak daha gelişmiş bir zeminde yapılmasına olanak sunmaktadır. Ayrıca YEM yaklaşımlarının tutarlı bir şekilde araclık rolü sonucunu tespit etmede birinci nesil regresyon yaklaşımından daha güçlü bir yeni nesil analiz yöntemi olduğu savunulmaktadır (Iacobucci vd., 2007). Gerek çalışmada birden fazla değişkenin bir arada analiz edilmesinden ötürü gerekse de araştırma modelinde aracı değişkenin rolünün tespit edilmesi amaçlandığından, YEM yönt- 
eminin çalışma için en uygun yöntem olduğuna karar verilmiştir. Bu bağlamda test edilmek üzere önerilen model Şekil 1'de verilmiştir.

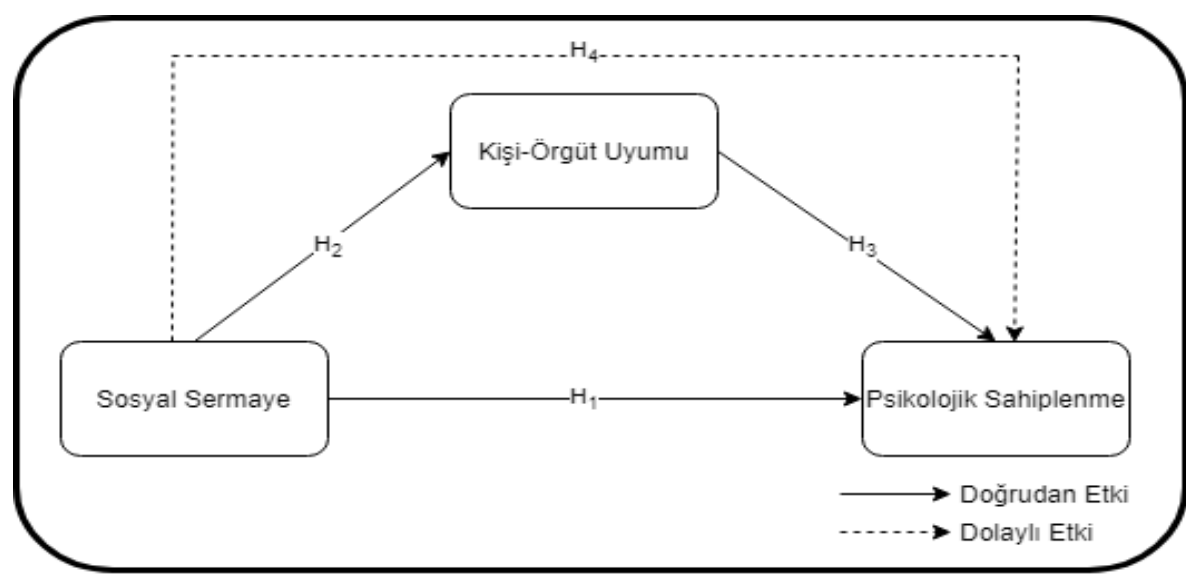

Şekil 1. Araştırma Modeli

Araştırma modeli Şekil 1'de görüldüğü gibidir. Model, Anderson ve Gerbing (1988) tarafından önerilen, verileri ve hipotezleri test etme adımlarından oluşan iki aşamalı yaklaşıma göre analiz edilmiştir. Bu bağlamda öncelikle uyuşum ve ayırt edici geçerliliği test etmek için ölçüm modeli kurulmuştur. Daha sonra hipotezleri test etmek için yapısal model kurulmuştur. Veriler, AMOS 26 ve SPSS 26 programları ile analiz edilmiştir.

\section{Katılımcilar}

Araştırmanın ana kütlesi, Polis Meslek Eğitim Merkezlerinde eğitim gören öğrencilerden oluşmaktadır. Ana kütlenin tamamına erişmek mümkün olmadığından örnekleme yapılmıştır. Örnekleme için kolayda örnekleme yönteminden yararlanılmıştır. Bu yöntemin seçilmesinin temel sebebi erişebilirlik açısından araştırmacıya büyük kolaylık sağlamasıdır (Bryman, 2016). Örneklem büyüklüğüyle ilgili net bir veriye ulaşılamadığından ötürü, örneklem büyüklüğü güç analizi yöntemiyle belirlenmiştir (Faul vd., 2007). Bu bağlamda, istatistiksel güce dayalı örneklem büyüklügünü hesaplamak için $\mathrm{G}^{*}$ Power v3.1.9.6 programından yararlanılmıştır. 0.95 istatistiki güç ile yapılan analiz sonucunda, modelimiz için tutarlı sonuç elde etmede, 
örneklem büyüklüğünün 121 olması gerektiği belirlenmiştir. Araştırmaya 259 öğrenci katıldığından, örneklem büyüklügünün tutarlı bir yapısal eşitlik modellemesi analizi için yeterli olduğu kabul edilmiştir.

Katılımcıların profili incelendiğinde $\% 17,4^{\prime}$ ün $(n=45) 22-23$ yaş aralığında; \%34,4'ünün $(n=89) 24-25$ yaş aralığında; \%81'in $(n=31,3) 28-29$ yaş aralığında; \%17'nin ise $(n=44) 30$ yaş ve üzerinde olduğu görülmektedir. Katılımcların \%10'unun ( $n=26)$ emniyet mensubu yakını varken, \%90' $1(n=$ 233) emniyet mensubu yakına sahip değildir. Eğitim durumları incelendiğinde, \%22'sinin ( $n=57)$ ön lisans mezunu olduğu; \%74,5'inin $(n=$ 193) lisans mezunu olduğu; \%3,5'inin $(n=9)$ ise lisansüstü eğitim gördüğ ü belirlenmiştir. Eğitim alanları incelendiğinde \%35,5 ile $(n=92)$ en yüksek kategorinin sosyal, beşerî ve idari bilimler olduğu, en düşük olanın ise $\% 0,4$ ile $(n=1)$ güzel sanatlar olduğu tespit edilmiştir.

\section{Ölçüm Araçları}

Köprï Kuran Sosyal Sermaye Ölçeği: Çalışmanın bağımsız değişkeni olan sosyal sermayeyi ölçmek için Steinfield vd. (2008) tarafından geliştirilen ve 8 maddeden oluşan köprü kuran sosyal sermaye ölçeği uyarlanmıştır. Örnek ölçek maddeleri: "Polis okulunda olup bitenlerle ilgilenirim" ve "Polis okulunun genel faaliyetlerine destekte bulunmak için zaman geçirmeye hazırım".

Psikolojik Sahiplenme Ölçeği: Araştırmanın bağımlı değişkeni olan psikolojik sahiplenmeyi ölçmek için Van Dyne ve Pierce (2004) tarafından geliştirilen ve 7 maddeden oluşan ölçek uyarlanmıştır. Orijinal formunda ölçeğin 7. maddesi ters kodlanmıştır. Anket uygulanırken bu uygulamaya sadık kalınmıştır. Örnek ölçek maddeleri: "Polis okulu için çok yüksek bir kişisel sahiplenme hissediyorum" ve "Polis okulunun bir üyesiymişim gibi düşünmek benim için zor (R)" şeklindedir.

Birey-Örgüt Uyumu Ölçeği: Çalışmada aracı değişken olan birey-örgüt uyumunu ölçmek için Netemeyer vd. (1997) tarafından geliştirilen ve 4 maddeden oluşan ölçek uyarlanmıştır. Örnek ölçek maddeleri: "Kişisel değerlerimin polis okuluyla iyi bir uyum içinde olduğunu düşünüyorum" 
ve "Polis okulunun değerleri, benim dürüstlükle ilgili düşüncelerimle uyumludur" tarzındadır.

Kullanılan ölçeklerin tamamı 5'li Likert tipindedir ve ölçek aralıkları 1Hiç Katılmıyorum, 5-Tamamen Katılıyorum şeklinde kodlanmıştır. Ortak yöntem yanlılığını ve sosyal arzu edilirlik yanlılığını en aza indirmek için anket, Podsakoff vd. (2003) tarafından yapılan önerilere göre tasarlanmıştır. Çalışmada ortak yöntem yanlılığı hatası olmadığını tespit etmek için toplanan veriler Harman'ın (1960) tek-faktör testine tabi tutulmuştur. Döndürme yöntemi uygulanmadan tek faktör altında incelenen verilerin açıklanan varyansı \%35,12'dir. Bu değer kabul edilebilir sınır olan \%50'nin oldukça altında olduğundan çalışmada ortak yöntem yanlılı̆̆ hatasının olmadığına kanaat getirilmiştir (Kline, 2015).

\section{Ölçüm Modeli}

Araştırmada hipotezleri test etmeden önce Anderson ve Gerbing (1988) tarafından yapısal eşitlik modellemesi için önerilen ilk adım olan ölçüm modeli kurulmuştur. Bu model kurulmadan önce SPSS 26 programı ile veriler gözden geçirilmiştir. Öncelikle eksik veriler gözden geçirilip kayıp veri olmaması sağlanmıştır. Daha sonra dağılımın normalliği test edilmiştir. Bu amaçla tek değişkenli ve çoklu değişkenli olmak üzere verilerin normalliği tek tek ve bir arada kontrol edilmiştir. Öncelikle verilerin çarpıklık ve basıklık değerleri incelenmiştir. Tüm değişkenler için çarpıklık ve basıklık değerlerinin $\pm 1,5$ seviyesinde olduğu görülmüştür. Bu değerler Kline (2015) tarafından önerilen sınırlar içerisinde olduğundan tek değişkenli normallik kriterinin sağlandığı belirlenmiştir. Çok değişkenli normallik dağılımı testi için Mardia (1970) katsayısından yararlanılmıştır. Yapılan analizler sonucunda, tüm gözlenen değişkenler için Mardia katsayısına göre dağılımın normal olduğu görülmüştür. Bunun yanı sıra ölçeklerde doğrudaşlık sorunu olup olmadığ 1 ve ölçek güvenilirlikleri incelenmiştir. Bu analizlerin sonuçları tablo 1'de paylaşılmıştır.

Tablo 1. Normallik, Doğrudaşlık, Güvenilirlik Analizi Sonuçlar

\begin{tabular}{llllll}
\hline Değişkenler & Çarpıklık & Basıklık & Tolerans & VIF & Alpha \\
\hline Sosyal Sermaye & $-0,433$ & $-0,422$ & 0,632 & 1,582 & 0,824 \\
Birey-Örgüt Uyumu & 0,020 & $-0,610$ & 0,709 & 1,409 & 0,803 \\
Psikolojik Sahiplenme & 0,836 & $-0,745$ & 0,650 & 1,539 & 0,821 \\
\hline
\end{tabular}


Tablo 1'den de anlaşılacağı üzere ölçeklerin VIF değeri kabul edilebilir sınır olan 5'in oldukça altında olduğundan çoklu bağlantı sorunu yoktur (Craney ve Surles, 2002). Ayrica ölçeklerin Cronbach alpha değerleri kabul edilebilir sınır olan 0,70'in üzerindedir. Yapısal eşitlik modellemesi için ön koşullar sağlandığından yapı geçerliliği ve güvenirliğini doğrulamak için AMOS 26 programı ile bir ölçüm modeli kurulmuştur. Fornell ve Larcker (1981) yapısal modelde anlamlı bir ilişki için test yapmadan önce, ölçüm modelinin yeterli düzeyde bir geçerlilik ve güvenilirliğe sahip olduğunun kanıtlanması gerektiğini savunmuştur. Bunun için ölçek maddelerinin 0,50'den daha yüksek bir faktör yüküne sahip olmasl, varyans tahmin değerlerinin (AVE) 0.50'den yüksek olması, kompozit güvenilirlik (CR) değerinin 0,60'dan büyük olması beklenmektedir. Ayrıca, ayrışım geçerliliği için AVE değerlerinin karekökünün değişkenler arasındaki korelasyon değerinden yüksek olması gerekmektedir (Fornell ve Larcker, 1981). Ölçeklere ilişkin geçerlilik ve güvenilirlik analizleri sonuçları ve tanımlayıcı bilgiler Tablo 2' de verilmiştir.

Tablo 2. Tanımlayıcı İstatistikler

\begin{tabular}{llllllll}
\hline & Ort. & SS. & CR & AVE & $\mathbf{1}$ & $\mathbf{2}$ & 3 \\
\hline 1. Sosyal Sermaye & 4,019 & 0,616 & 0,814 & 0,476 & $\mathbf{( 0 . 6 9 0 )}$ & & \\
2. Birey-Örgüt Uyumu & 4,274 & 0,624 & 0,805 & 0,521 & $0.468^{* * *}$ & $\mathbf{( 0 . 7 2 2 )}$ & \\
3. Psikolojik Sahiplenme & 4,184 & 0,604 & 0,872 & 0,540 & $0.585^{* * *}$ & $0.445^{* * *}$ & $\mathbf{( 0 . 7 3 5 )}$ \\
\hline
\end{tabular}

${ }^{* * *} p<0.001 ;$ Ort. $=$ Ortalama; $S S=$ Standart Sapma; Parantez İçi Koyu Değerler $=\sqrt{ } A V E$

Kurulan ölçüm modelinin uyum iyiliği değerlerinin kabul edilebilir sinurlar içerisinde (Hu ve Bentler, 1999) olduğu görülmüştür $\chi^{2} / \mathrm{df}=2,118$; RMSEA $=0,066$; NFI =0,910; TLI =0,936; CFI =0,950; $\mathrm{SRMR}=0,049$. İlk yapılan analizde sosyal sermaye ve psikolojik sahiplenme ölçeklerinin CR ve AVE değerlerini sağlamadığı tespit edilmiştir. Bu nedenle sosyal sermaye ölçeğinin ilk maddesi ile psikolojik sahiplenme ölçeğinin 6. maddesi analizlerden çıkarılmıştır. Bu işlemin ardından psikolojik sahiplenme ölçeğinin AVE değerini sağladığı belirlenmiştir. Sosyal sermaye ölçeği ise kritik eşik olan 0,50'nin altında kalmıştır. AVE değeri 0,50 eşiğinin biraz altında olması konusunda Fornell ve Larcker (1981) CR değerinin kontrol edilmesini önermiştir. Buna göre araştırmacılar CR değeri 0,70 üzerinde olan yapılarda ölçek maddesi çıkarılmaması gerektiğini savunmuştur. Ölçeklerdeki tüm CR değerleri 0,80 'den yüksek olduğundan başka bir maddenin çıarıl- 
masına gerek duyulmamıştır. Tablo 2'den de anlaşılacağı üzere ölçeklerin uyuşum ve ayrışım geçerliliğini sağladığı görülmüştür.

\section{Yapisal Model}

Kurulan hipotezleri test etmek için AMOS 26 programinda "maximum likelihood" modeunda yapısal model kurulmuştur. Kurulan modelin kabul edilebilir (Hu ve Bentler, 1999) olduğu görülmüştür $\chi^{2}=326,268(87), \chi^{2} / \mathrm{df}=$ 3,750; RMSEA =0,078; NFI =0,933; TLI =0,944; CFI =0,970. Modelden elde edilen doğrudan etki analizi sonuçları Tablo 3'te verilmiştir.

Tablo 3. Doğrudan Etki Analizi Sonuçlar

\begin{tabular}{lllll}
\hline Hipotezler & Katsayi $^{1}$ & S.H. & K.O. & $p$ \\
\hline H1: Sosyal Sermaye $\rightarrow$ Psikolojik Sahiplenme &, 483 &, 098 & 5,846 & 0,000 \\
H2: Sosyal Sermaye $\rightarrow$ Birey-örgüt Uyumu &, 468 &, 059 & 5,139 & 0,000 \\
H3: Birey-örgüt Uyumu $\rightarrow$ Psikolojik Sahiplen- &, 219 &, 135 & 2,946 & 0,003 \\
me & & & & \\
\hline
\end{tabular}

${ }^{1}$ Standardize Edilmiş Katsayılar Verilmiştir; S.H. = Standart Hata; K.O. = Kritik Oran

Kurulan yapısal eşitlik modelindeki ilişkiler incelendiğinde sosyal sermayenin, psikolojik sahiplenme $(\beta=0,483$; $\mathrm{p}<0.001)$ ve birey-örgüt uyu$\mathrm{mu}(\beta=0,468 ; \mathrm{p}<0.001)$ üzerinde pozitif yönlü ve anlamlı bir etkiye sahip olduğu görülmüştür. Birey-örgüt uyumunun ise psikolojik sahiplenme ( $\beta=$ 0,219; $\mathrm{p}<0.01)$ üzerinde pozitif ve anlamlı bir etkiye sahip olduğu belirlenmiştir. Araştırmanın bu bulgularına göre " $\mathrm{H}_{1}$ : Sosyal sermayenin psikolojik sahiplenme üzerinde pozitif yönlü etkisi vardır", " $\mathrm{H}_{2}$ : Sosyal sermayenin birey-örgüt uyumu üzerinde pozitif yönlü etkisi vardır" ve "H3: Birey-örgüt uyumu psikolojik sahiplenmeyi pozitif etkiler" hipotezleri kabul edilmiştir.

Modeldeki aracı etki analizlerini test etmek için Baron ve Kenny (1986) tarafından önerilen adımlar izlenmiştir. Araclık analizi, kitle parametresine ilişkin güven aralığının hesaplanmasına olanak sağlayan bootstrap yöntemi ile yapılmıştır. Araştırmada bootstrap örneklem büyüklüğü 2000 olarak belirlenmiştir. Aracılık analizi sonuçları Tablo 4'te paylaşılmıştır. 
yönlü bir etki yapabileceği beklenmekteydi. Yapılan analizler sonucu bu varsayımın doğrulandığı, bir başka deyişle, sosyal sermayenin birey-örgüt uyumuna olumlu bir etki yaptığı sonucuna ulaşılmıştır. Dolayısıyla ikinci hipotez desteklenmiştir.

Araştırmacilar, bireylerin örgüt değerleriyle ortak bir paydada buluştukları ölçüde örgütleriyle uyumlu olduğunu vurgulamaktadır (Chatman, 1989). Birey-örgüt uyumu yüksek olan bireylerin ise örgütlerine daha çok bağlılık gösterip, örgütsel vatandaşlık davranışları sergiledikleri bildirilmektedir (Erkutlu, 2015). Buradan yola çıkarak, çalışmamızda örgütleriyle uyumlu olan bireylerin sahiplenme davranışları geliştireceği öngörüldü. YEM analiz sonuçlarına göre birey-örgüt uyumunun psikolojik sahiplenmeye pozitif bir etki yaptığı sonucuna ulaşıldı. Dolayısıyla oluşturulan üçüncü hipotezimizin desteklendiği görüldü. Çalışmamızın bu bulgusu Rahmayanti ve Kurniawan'ın (2020) yürüttüğü çalışmaile benzeştiğini ifade etmek mümkündür.Çalışmamızın dördüncü hipotezi birey-örgüt uyumunun sosyal sermaye ile psikolojik sahiplenme ilişkisinde aracılık rolü üsteleneceği şeklindeydi. Yapılan istatistiksel analizler sonucu birey-örgüt uyumunun bahsi geçen iki değişken arasındaki ilişkiye aracılık yaptığı sonucuna ulaşıldı.

Çalışmamız psikolojik sahiplenme, sosyal sermaye ve birey-örgüt kavramlarını bir araya getirip yeni bir model oluşturması yönüyle özgündür. İlgili yazın incelendiğinde bu değişkenlerin ilişkilerini ampirik olarak inceleyen bir araştırma olmayışından hareketle, makalemiz yazındaki önemli bir boşluğu doldurduğu ifade edilebilir. Araştırmamız birey-örgüt uyumunu hem aracı rolünde hem de psikolojik sermayenin bir belirleyicisi olduğunu keşfeden ilk araştırma olması nedeniyle psikolojik sahiplenme ile ilgili bilinen yazını genişletmektedir.

Yürüttüğümüz araştırmanın sonuçlarına göre yöneticiler ve çalışanları için bir takım önerilerde bulunulabilir. Öncelikle yöneticiler işe alım süreçlerinde sosyal sermayesi yüksek bireyleri tespit edebilecek seçme sistemleri kurabilir. Personel seçiminde kurumun değerlerinin ve özelliklerinin işe alınacak kişilerdeki örtüşme derecesine dikkat edilmesi önerilir çünkü, birey-örgüt uyumu psikolojik sahiplenmeyi arttırmaktadır. Sosyal sermayesi yüksek bireylerin tercih edilmesi çalışanların, kuruma bağlılığın bir göstergesi olan, psikolojik sahiplik duygularını arttırabilir. Bununla birlikte yöneticilerin birlikte çalışmayı teşvik eden, sosyal ilişkiler geliştirebilecek bir ku- 
rum kültürü oluşturması çalışanların örgütlerine sahiplik hissetmesine yardımcı olabilir.

Araştırmamız, her ne kadar orijinal bir model kurup hipotezlerini test etmiş olsa da bazı sınırlılıkları bulunmaktadır. Araştırma modelimizde sosyal sermayenin kurumun psikolojik olarak sahiplenilmesinde rol oynadığı sonucuna ulaşılmış olsa da psikolojik sahiplenmeyi etkileyebilecek başka faktörlerin etkilerine bakılabilir. Örneğin; çalışanların psikolojik iyi oluşu, çalışanların güçlendirilmesi veya örgütsel güven gibi çeşitli değişkenlerin psikolojik sahiplenme ile olan ilişkisi araştırılabilir. Öte yandan çalışmamızda birey-örgüt uyumunun aracılık rolü incelenmiş ise de gelecekteki araştırmalar örgütsel sinizm, örgütsel dedikodu veya örgütsel yabancılaşma gibi olumsuz tutum ve davranışların aracilık etkisini ele alabilir. Çalışmamız bir kamu kurumundan 259 katılımcıdan elde edilen verilerle gerçekleştirildiğinden genelleme yapmak oldukça güçtür. Gelecekteki araştırmalar birden fazla kurumdan örneğin kamu veya özel sektörden veri toplayıp çeşitli karşılaştırmalar yapabilir. 


\title{
EXTENDED ABSTRACT
}

\section{Interrogating the Relationships between Bridging Social Capital, Psychological Ownership and Person-Organization Fit}

\author{
Gökhan Uludağ - Berat Çiçek - Mehmet Ali Türkmenoğlu \\ Security Department- Malatya Turgut Özal University - Muş Alparslan University
}

Over the last a few decades, there has been an increase in the number of studies which examine constructs that have impacts on performance of employees and organizations. One recent concept is psychological ownership which was based on the idea of ownership by Pierce and the associates. It is based on the notion that even if the individual does not have a formal ownership of the organization, he/she feels that he/she owns the organization (Pierce, Rubenfeld and Morgan, 1991; Pierce, Kostova and Dirks, 2001). When psychological ownership occurs, the individual develops feelings of commitment and responsibility towards the organization. Consequently, as studies indicate, individuals' sense of belonging to their organization increases (Derin, 2018). Although many empirical studies investigated the effects of psychological ownership on different constructs, antecedents of psychological ownership remained relatively understudied. In this context, considering that psychological ownership is a relatively new phenomenon and its relationship with other variables not known well, it can be argued that more studies are needed in this intersection.

Social capital is defined as the ability of people to work together as a group or as an organization to achieve their goals (Coleman, 1988). It is described social capital when more than one individual come together to form a trust based network. Individual-organization fit is defined as the level of harmony between the characteristics of the individual and the characteristics of the organization. The individual-organization fit is also expressed as the compatibility between individual value judgments and the organization's value judgments (Goodman ve Svyantek, 1999). It is argued that social capital is an important factor in bringing people from different cultures together to establish a network for exchanges. Considering the positive role of social capital in relations, we wonder if it will have an effect on psychological ownership. Moreover, we wondered the relationship between social capital, psychological ownership and personorganization fit in this study. Hence, the aim of this study is to examine the ef- 
fect of social capital on psychological ownership and determine the mediating role of person-organization fit in the relationship between these two variables. To examine these relationship we posited four hypotheses.

In order to test the hypotheses, a cross-sectional research was designed. For analyzing the data obtained from 259 Police Vocational Training Centers' students, structural equation modeling (SEM) was employed. To increase the response rate, drop-off and pick-up method (Lovelock et al., 1976) was adopted in the research. For defining sample size, the Power Analysis procedure was followed (Faul et al., 2007). Accordingly, a sample size of 121 is sufficient with a statistical power of 0.95 for the model used in the research. Since the sample size is 259 , it can be said that sample size is sufficient for the model.

In the first step of the analysis, a measurement model was established to test the construct validity, reliability, convergent and discriminant validity. According to the values obtained in the measurement model, it was concluded that the data did not pose any problems in terms of structure validity and reliability. According to the results of the structural model, it was concluded that social capital affects psychological ownership $(\beta=, 483)$, and person-organization fit ( $\beta$ $=, 468)$ positively. In addition, it was seen that person-organization fit affects psychological ownership $(\beta=, 219)$ positively. The steps suggested by Baron and Kenny (1986) were followed with the bootstrapping method to determine the mediating role of person-organization fit in the research. Accordingly, the results of the mediation analysis shown that person-organization fit mediates the relationship between social capital and psychological ownership.

Our model, which was formed in the light of hypotheses established with the support literature, is original and it has never been studied together before. When the related literature is examined, we argue that our article fills an important gap in the literature. In other words, our research expands the known literature on psychological ownership, as it is the first study to discover that individual-organization fit is both a mediator and a determinant of psychological capital.

According to the results of the research, some suggestions can be made for managers. Managers can establish selection systems that can identify individuals with high social capital in their recruitment processes. It is recommended to pay attention to the degree of overlap between the values and characteristics of the organization in personnel selection.

Although our research has established an original model and tested its hypotheses, it has some limitations. The effects of other factors e.g. employee well- 
being that can affect psychological ownership can be examined in future studies. Since our study was conducted with data from 259 participants from a public organization, it is very difficult to generalize the results. Future studies may expand the number of participants as well as the number of organizations.

\section{Kaynakça / References}

Akçin, K. (2018). Çalı̧anların örgütsel destek algisı ve psikolojik sahiplenmelerinin, sessizlik davranışlarına ve görev performansına etkisi: Eğitim sektöründe bir araştırma. Yayınlanmamış doktora tezi. Uludağ Üniversitesi Sosyal Bilimler Enstitüsü, Bursa.

Anderson, J. C. ve Gerbing, D. W. (1988). Structural equation modeling in practice: A review and recommended two-step approach. Psychological Bulletin, 103(3), 411-423.

Başaran, İ.E. (2004). Yönetimde insan ilişkileri yönetsel davranış. 3. Baskı, Ankara: Nobel Yayın Dağıtım

Bryman, A. (2016). Social research methods. London: Oxford University Press.

Brown, G., Crossley C., ve Robinson, S.L., (2014). Psychological ownership, territoral behavior, and being perceived as a team contributor: The critical role of trust in the work environment, Personnel Psycho$\log y, 67,463-485$.

Bowen, D. E., Ledford, G. E., Nathan, B. R. (1991).Hiring for the organization not the job. Academy of Management Executive, 5(4), 35-51.

Bourdieu, P. (1986). The forms of capital. In J. G. Richardson (Eds.), Handbook of theory and research for the sociology of education. New York, NY: Greenwood Press, 241-258.

Callois, J. M. ve Aubert, F. (2005). Towards indicators of social capital for regional development issues .www.regional-studies-assoc.ac.uk/ events/ aalborg05/callois.01.12.2021

Chatman, J. A. (1989). Improving interactional organizational research: A model of person organization fit. Academiy of Management Review, 14(3), 333-349

Coleman, J.S. (1988). Social capital in the creation of human capital, The American Journal of Sociology, 94, 95-120

Craney, T. A. ve Surles, J. G. (2002). Model-dependent variance inflation factor cutoff values. Quality Engineering, 14(3), 391-403. 
Çınar, Ö. ve Temelli F. (2017). Üniversite öğrencilerinin akademik başarılarını etkileyen örgütsel faktörler ölçeğinin geliştirilmesi: Ağrı İbrahim Çeçen Üniversitesi örneği, A $\breve{g} r$ İbrahim Çeçen Üniversitesi Sosyal Bilimler Enstitüsü Dergisi, 3(2), 33-55

Derin, N. (2018). Kuruma duyulan psikolojik sahiplenme ile yenilikçi iş davranışı arasındaki ilişkide sanal kaytarmanın düzenleyici rolü. Hacettepe Üniversitesi İktisadi ve İdari Bilimler Fakültesi Dergisi, 36(1), 63-81.

Doney, P. M. ve Cannon, J. P. (1997). An examination of the nature of trust in buyer- seller relationships. Journal of marketing, 61(2), 35-51.

Erkutlu H.V. (2015). Pozitif örgütsel davranış. Ankara: Akademisyen Kitabevi.

Eşki, H. (2009). Sosyal sermaye- önemi, üretimi ve ölçümü-üzerine bir alan araştırması, Doktora Tezi, Selçuk Üniversitesi Sosyal Bilimler Enstitüsü, Konya.

Etcheverry, E. (1996). Social capital: A resource for the human capital development of university students., Faculty of Education, Doctorate Thesis, University of Manitoba, Manitoba.

Faul, F., Erdfelder, E., Lang, A. G., ve Buchner, A. (2007). G*Power 3: A flexible statistical power analysis program for the social, behavioral, and biomedical sciences. Behavior research methods, 39(2), 175-191.

Fornell, C., ve Larcker, D. F. (1981). Evaluating structural equation models with unobservable variables and measurement error. Journal of Marketing Research, 18(1), 39-50.

Fukuyama, F. (2005). Güven, sosyal erdemler ve refahın yaratılması, Çev:Ahmet Buğdayc1, 3. Basım, İstanbul: Şefik Matbaası.

Gelman, S. A., Manczak, E. M. ve Noles, N. S. (2012). The nonobvious basis of ownership: preschool children trace the history and value of owned objects, Child Development, 83(5), 1732-1747.

Gerşil, G. S. ve Aracı, M. (2011). Sosyal sermayenin güven unsurunun işgörenlerin performansı üzerine etkileri. Çalışma ve Toplum, 1, 39-74.

Goodman, S.A. ve Svyantek D.J. (1999). Person-organization fit and contextual performance: Do shared values matter. Journal of Vocational Behavior 55(2), 254- 275.

Hanifan, L. J. (1916). The rural school community center, Annals of the American Academy of Political and Social Science, say1 67,

Harman, H. H. (1960). Modern factor analysis. Oxford, England: Univ. of Chicago Press. 
Harpham, T. (2008). The measurement of community social capital through surveys. Social Capital and Health. Ed. Ichirō Kawachi - S. V. Subramanian - Daniel Kim. 51-62. New York ; London: Springer,

Hu, L. ve Bentler, P. M. (1999). Cutoff criteria for fit indexes in covariance structure analysis: Conventional criteria versus new alternatives. Structural Equation Modeling: A Multidisciplinary Journal, 6(1), 1-55.

Işık, M., Çiçek, B. (2020). Planlı davranış teorisi perspektifinden girişimcilik niyeti üzerinde sosyal sermaye öz yeterlilik ve öz saygının rolü. Turkish Studies - Economy, 15(1), 185-206.

Işık, M., Çiçek, B. ve Karakaş, Y. E. (2019). Sosyal sermaye üniversite yaşamından tatmini nasıl etkiler? Uluslararası İktisadi ve İdari Bilimler Kongresi, Şırnak, 608-618.

Jih, W.K. ve Lee, Y.T. (2007). Effects of service quality and shared value on trust and commitment: An emprical study of 3CS product customesr in Taiwan, International Journal of Business Studies, 15(2), 83-98

Jussila, L., Tarkiainen, A., Sarstedt, M. ve Hair, J. F. (2015). Individual psychological ownership: Concepts, evidence, and implications for research in marketing. Journal of Marketing Theory and Practice, 23(2), 121-139.

Karagül, M. ve Dündar, S. (2006). Sosyal sermaye ve belirleyicileri üzerine ampirik bir çalışma. Akdeniz Üniversitesi İ̈BF Dergisi, 6(12), 61-78.

Kristof, A. L. (1996). Person-organization fit: An integrative review of its conceptualizations, measurement, and implications. Personnel psychology, 49(1), 1-49.

Kline, R. B. (2015). Principles and practice of structural equation modeling. Guilford Publications.

Iacobucci, D., Saldanha, N. ve Deng, X. (2007). A meditation on mediation: Evidence that structural equations models perform better than regressions. Journal of Consumer Psychology, 17(2), 139-153.

Lovelock, C. H., Stiff, R., Cullwick, D. ve Kaufman, I. M. (1976). An evaluation of the effectiveness of drop-off questionnaire delivery. Journal of Marketing Research, 13(4), 358-364.

Mayhew, M. G., Ashkanasy, N. M., Bramble, T. ve Gardner, J. (2007). A study of the antecedents and consequences of psychological ownership in organizational settings. The Journal of social psychology, 147(5), 477-500. 
Mahsud, M. ve Hao, j. (2017). Measurement and Comparison of Psychological Ownership in Public and Private Service Organizations, International Conference on Service Systems and Service Management, China, 0106 June 2017.

Mardia, K. V. (1970). Measures of multivariate skewness and kurtosis with applications. Biometrika, 57(3), 519-530.

Muchinsky, P.M. ve Monahan, C.J. (1987). What is person-environment congruence: Supplementary versus complementary models of fit. Journal of Vocational Behavior 31(3),268-277.

Netemeyer, R. G., Boles, J. S., McKee, D. O. ve McMurrian, R. (1997). An investigation into the antecedents of organizational citizenship behaviors in a personal selling context. Journal of marketing, 61(3), 85-98.

O'Reilly, C.A. (2002). The wrong kind of "ownership. Across the Board, 39(5), 19-20.

Öğüt, A. ve Erbil, C. (2009). Sosyal sermaye ve yönetimi (2. Baskı). Konya: Çizgi Kitabevi.

Ötken, A. (2015). Algılanan örgütsel destek ve psikolojik sahiplenme arasındaki ilişki ve bu ilişkide örgütsel adaletin rolü. Hacettepe Üniversitesi İktisadi ve İdari Bilimler Fakültesi Dergisi, 33(2), 113-140.

Pennington, M., (2014). Sağlam politik ekonomi, Klasik Liberalizm ve Kamu politikasının geleceği, Çev: Atilla Yayla, Ankara: Liberte Yayınları/179.

Pierce, J. L. ve Jussila, I. (2011). Psychological ownership and the organizational context, MPG Books Group, UK.

Pierce, J. L., Kostova, T. ve Dirks, K. T. (2001). Toward a theory of psychological ownership in organizations. Academy of management review, 26(2), 298-310.

Pierce, J. L., Rubenfeld, S. A. ve Morgan, S. (1991). Employee ownership: A conceptual model of process and effects. Academy of Management review, 16(1), 121-144.

Podsakoff, P. M., MacKenzie, S. B., Lee, J. Y. ve Podsakoff, N. P. (2003). Common method biases in behavioral research: a critical review of the literature and recommended remedies. Journal of applied psychology, 88(5), 879.

Putnam, R. D. (2001). Alone Bowling The Collapse and Revival of American Community. Simon and Schuster. 
Rahmayanti, N. ve Kurniawan J. E. (2020). Relationship between person job fit and psychological ownership in the successor of family business, in 6th International Conference on Entrepreneurship (ICOEN) 2019, KnE Social Sciences, p.64--71.

Reyhanoğlu, M. (2006). AR-GE işbirliklerinde güven: Ankara'daki teknoparklarda faaliyet gösteren işletmelerde bir araştırma, Yayımlanmamış Doktora Tezi, Ankara Üniversitesi Sosyal Bilimler Enstitüsü, Ankara.

Robbins, S.P. ve Judge, T.A. (2017). Örgütsel davranış, Çev: İnci Erdem. Ankara: Nobel Akademik Yayıncılık.

Saldamlı, A. (2009), İşletmelerde örgütsel bağlılık ve işgören performansı, Ankara: Detay Yayıncilik.

Silverthorne, C. (2004). The impact of organizational culture and personorganization fit on organizational commitment and job satisfaction in Taiwan. Leadership E Organization Development Journal. 25(7), 592599.

Steinfield, C., Ellison, N. B. veLampe, C. (2008). Social capital, self-esteem, and use of online social network sites: A longitudinal analysis. Journal of Applied Developmental Psychology, 29(6), 434-445.

Steinfield, C., Ellison, N. B. ve Lampe, C. (2008). Social capital, self-esteem, and use of online social network sites: A longitudinal analysis. Journal of applied developmental psychology, 29(6), 434-445.

Şahin, M. M. ve Y1lmaz, O. (2020). sosyal sermaye, motivasyon ve iş tatmini arasındaki aracılık etkisi: Batman Üniversitesi örneği. Yönetim ve Ekonomi: Celal Bayar Üniversitesi İktisadi ve İdari Bilimler Fakültesi Dergisi, 27(3), 587-606.

Temple, J. (2000). Growth effect of education on social capital in the OECD Countries, OECD Working Paper No: 00/36.

Turunç, Ö. ve Çelik, M. (2012). İş tatmini-kişi-örgüt uyumu ve amire güvenkişi-örgüt uyumu ilişkisinde dağıtım adaletinin düzenleyici rolü. Is, Guc: The Journal of Industrial Relations \& Human Resources, 14(2),57-78.

Tüysüz, N. (2011). Sosyal sermayenin ekonomik gelişme açısından önemi ve sosyal sermaye endeksinin hesaplanması, Uzmanlık Tezi, Kalkınma Bakanlığı, Ankara.

Ulutaş, M. (2011). Harmonik yönetim (Birey-örgüt uyumu), Konya: Ulvita Yayıncilik. 
Uçar, Z. (2017). Psikolojik sahiplenme: Örgütsel alana ilişkin bir model önerisi, Dokuz Eylül Üniversitesi İktisadi ve İdari Bilimler Fakültesi Dergisi, 32(1), 167- 200.

Xiaojun, W. ve Peilan, G. (2009). The application of person-organization fit to the practice of human resource management. Fourth International Conference on Computer Sciences and Convergence Information Technology, 636-640.

Xiaojun, W. ve Shizong, L. (2010). The research on knowledge worker's personorganization Fit, IEE, Computer Society.

Van Dyne, L. ve Pierce, J. L. (2004). Psychological ownership and feelings of possession: Three field studies predicting employee attitudes and organizational citizenship behavior. Journal of Organizational Behavior: The International Journal of Industrial, Occupational and Organizational Psychology and Behavior, 25(4), 439-459.

Verquer, M. L., Beehr, T. A. ve Wagner, S. H. (2003). A meta-analysis of relations between person-organization fit and work attitudes. Journal of vocational behavior, 63(3), 473-489.

Wagner, S.H, Parke, C.P. ve Christiansen, N.D. (2003). Employees that think and act like owners: Effects of ownership beliefs and behaviors on organizational effectiveness, Personel Psychology, 56(4), 847-871.

Weston, R. ve Gore Jr., P. A. (2006). SEM 101: A brief guide to structural equation modeling. The Counseling Psychologist, 34, 719-751.

Yıldız, B. (2016). Postmodern örgütlerde güncel davranışsal konular, (1.Baskı), İstanbul: Beta Yayıncılık.

\section{Kaynakça Bilgisi / Citation Information}

Uludağ, G., Çiçek B. ve Türkmenoğlu, M. A. (2021). Köprü kuran sosyal sermaye, psikolojik sahiplenme ve birey-örgüt uyumu arasidaki ilişkilerin incelenmesi. OPUS-Uluslararası Toplum Araştırmaları Dergisi, 18(Yönetim ve Organizasyon Özel Sayısı), 1337-1364. DOI: $10.26466 /$ opus. 867368 . 